
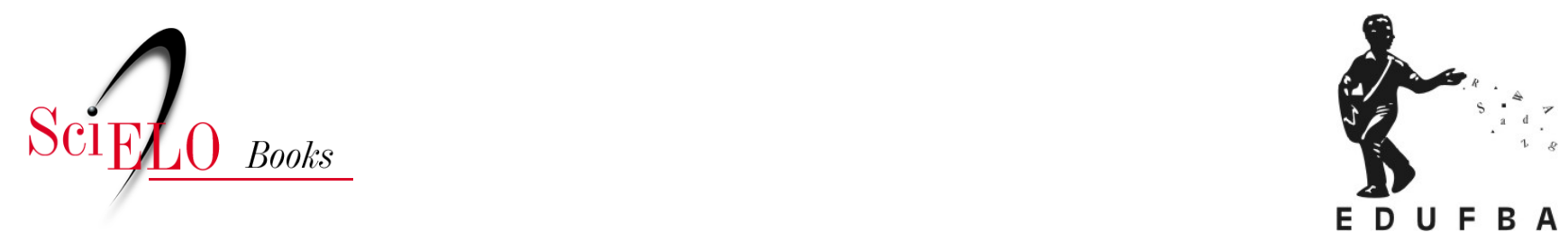

\title{
O Sonho Metalúrgico? \\ Trabalho, desenvolvimento e adoecimento no contexto de um complexo automotivo
}

\author{
Jorge Henrique Santos Saldanha \\ Mônica Angelim Gomes de Lima \\ Robson da Fonseca Neves
}

\section{SciELO Books / SciELO Livros / SciELO Libros}

SALDANHA, J.H.S., LIMA, M.A.G., and NEVES, R.F.N. O Sonho Metalúrgico? Trabalho, desenvolvimento e adoecimento no contexto de um complexo automotivo. In: LIMA, M.A.G., FREITAS, M.C.S., PENA, P.G.L., and TRAD, S., orgs. Estudos de saúde, ambiente e trabalho: aspectos socioculturais [online]. Salvador: EDUFBA, 2017, pp. 9-31. ISBN: 978-85-232-1864-5. http://doi.org/10.7476/9788523218645.0002

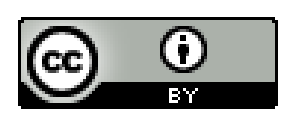

All the contents of this work, except where otherwise noted, is licensed under a Creative Commons Attribution $\underline{4.0 \text { International license. }}$

Todo o conteúdo deste trabalho, exceto quando houver ressalva, é publicado sob a licença $\underline{\text { Creative Commons }}$ Atribição 4.0. 


\title{
O Sonho Metalúrgico? Trabalho, desenvolvimento e adoecimento no contexto de um complexo automotivo
}

\author{
JORGE HENRIQUE SANTOS SALDANHA \\ MONNICA ANGELIM GOMES DE LIMA \\ ROBSON DA FONSECA NEVES
}

"A expectativa era muito grande. Acho que no meu caso particularmente, para eu trabalhar numa montadora, saber falar em fabricar um carro, para mim, (suspiro) Ave Maria, era tudo! E aí foi que o sonho virou realidade”. (Fala de João, metalúrgico, sobre a expectativa de entrar no CIEN) ${ }^{1}$

A epígrafe acima revela o imaginário presente nos trabalhadores do município de sede, Camaçari, quando ocorreu a instalação do CIEN na cidade. A chegada de uma empresa multinacional na cidade, trazida no contexto de uma política macroeconômica de migração de capitais para regiões periféricas e de uma política de desenvolvimento regional da indústria brasileira, animava os trabalhadores da cidade, que viam na chegada do CIEN a oportunidade de conquistar um trabalho fixo, melhoria das condições de vida e reconhecimento social, já que apesar da expansão industrial, que a

1 Complexo Industrial Empresa Nordeste. 
cidade tinha vivido no ciclo anterior motivado pela indústria petroquímica, não ter produzido na cidade a formação de um contingente de trabalhadores industriários com boas condições de vida, pois o setor petroquímico, mesmo instalado no município, absorveu, como emprego primário, operários qualificados que moravam em Salvador, deixando para os moradores do município sede os empregos terceirizados.

O município sede, ao qual se refere aqui, está situado na região metropolitana de Salvador (RMS) a $41 \mathrm{~km}$ da capital. Tem uma população aproximada de 242.984 mil habitantes, sendo 120.626 homens e 122.358 mulheres. (IBGE, 2010) Possui o maior PIB (Produto Interno Bruto) industrial do Nordeste, de $\mathrm{R} \$ 8$ bilhões, e sua economia corresponde a 8,67\% do PIB estadual. Esse cenário é possível, graças à posição em que ocupa na industrialização baiana, correspondendo a 35\% da industrialização do estado, com isso o município possui o maior PIB per capita da Bahia. (IBGE, 2010)

O Complexo Industrial Empresa Nordeste tem capacidade para produzir 250 mil veículos por ano. A planta reúne sob o mesmo teto a empresa e 27 parceiros que fornecem sistemas para os veículos diretamente na linha de montagem em um sistema de condomínio industrial. ${ }^{2}$ A planta possui um alto padrão de automação industrial, contando com mais de 512 robôs e sistemas eletromecânicos de automação, com um modelo de produção chamado montagem modular sequenciada, aplicado pela primeira vez dentro da Empresa Mundial. Seu principal diferencial é a participação de fornecedores diretamente na linha de montagem e no processo de produção, e não apenas no fornecimento dos componentes do veículo, compartilhando das instalações e das responsabilidades. (FORD MOTOR COMPANY, [201-])

Ismar Sena (2009) destaca que, a partir da implantação do Regime Automotivo Especial, a Bahia recebeu o interesse de várias montadoras, que se habilitaram para construir empreendimentos em estados como Bahia, Ceará, Goiás, Tocantins e Acre. Vinte e cinco empresas haviam se comprometido a investir 3,53 bilhões de dólares nesses estados, sendo que a Bahia

2 O condomínio industrial é uma configuração, na qual alguns fornecedores escolhidos pelas montadoras se instalam junto às plantas das indústrias, objetivando reduzir custos em estoques, processos, transporte e facilitar a integração entre os parceiros. Os condomínios industriais permitem que as empresas centrais estabeleçam com outras empresas menores relações, mais distantes, de apenas entregas de pequenos lotes -Just in time - até o processo atual de fornecimento de subconjuntos ou subsistemas completos na linha de montagem, aumentando a corresponsabilidade das empresas no processo produtivo. (SALERNO; MARX; ZILBOVICIUS, 2003) 
receberia investimentos que representariam 50\% desse valor. Ao analisar o montante de isenções fiscais recebido pela empresa para instalar sua planta na Bahia, Sena (2009, p. 73) manifesta:

[...] É interessante observar que o total de incentivos concedidos à Empresa, que somaram à época $\mathrm{R} \$ 2.402$ bilhões seria suficiente para construir com sobras as fábricas das outras três montadoras, visto que a soma dos incentivos concedidos à Renault, General Motors e Mercedes foi da ordem de R \$ 1.804 bilhões.

É nesse cenário de incentivos fiscais vultosos e pouca ênfase dada às condições de trabalho dos milhares de trabalhadores e trabalhadoras, que ingressariam nessa corrida pelo ouro, motivados pelo fato de que o setor metalúrgico automotivo, apesar de novo no estado da Bahia, já aparece como um dos maiores setores da indústria, tanto no volume arrecadado quanto no número de empregos gerados. De fato o complexo industrial automotivo é responsável por cerca de nove mil empregos diretos, sendo que a maioria dos empregos está relacionada com a atividade de produção. (FIEB, 2010; SENA, 2009) Mas, questiona-se qual o impacto da instalação do CIEN nessa cidade e qual a relação desse processo produtivo com o adoecimento de trabalhadores metalúrgicos?

Neste capítulo descrevem-se: o contexto de implantação do complexo automotivo vivenciado pelos trabalhadores, as expectativas com a sua chegada, o processo de construção de uma identidade metalúrgica na cidade, o papel do trabalho como instrumento de satisfação na vida dos trabalhadores do complexo e o impacto econômico e social da instalação do CIEN na cidade. Ao longo das conversações, são descritas as contradições entre as expectativas e a realidade do processo produtivo vivenciada pelos metalúrgicos, assim como apontadas explicações emergentes sobre o modelo de produção como determinante no adoecimento no setor automotivo e nas relações entre os trabalhadores e as empresas.

\section{Caminhos metodológicos}

Trata-se de um estudo exploratório apoiado em uma abordagem etnográfica. As interlocuções nos levaram a aproximações com o contexto local de um município que sofreu inúmeras transformações em curto espaço de tempo com a implantação do CIEN. O recuso à descrição etnográfica 
exigiu explorar as cenas e a memória do lugar por meio dos relatos dos sujeitos, de pesquisa antes de adoecerem e da descrição da observação do pesquisador no diário de campo. Utilizamos também como técnica a entrevista narrativa com cinco informantes-chave atendidos no ambulatório do Centro de Referência em Saúde do Trabalhador (CEREST) do município. A escolha dos homens participantes do estudo se deu pela identificação dos técnicos do serviço, como bons interlocutores, e da busca dos prontuários pelo pesquisador.

A perspectiva teórica aqui adotada se alinha com o que Minayo (2010) chama de hermenêutica dialética, que integra uma interlocução com a hermenêutica de Gadamer, enquanto:

[...] busca da compreensão de sentidos, que se dá na comunicação entre indivíduos, baseando-se na experiência cultural e nas análises dos contextos e da práxis' e com a dialética, tomada como a 'ciência e arte do diálogo, da pergunta e da controvérsia, buscando nos fatos, na linguagem, nos símbolos e na cultura, os núcleos obscuros e contraditórios para realizar uma crítica informada sobre eles. (MINAYO, 2010, p. 166-167)

O posicionamento da autora quanto à complementariedade da hermenêutica e da dialética, enquanto "momentos necessários da produção de racionalidade em relação aos processos sociais e, por conseguinte, em relação aos processos de saúde e doença”, amplia o recurso à hermenêutica, em direção ao "entendimento dos textos, dos fatos históricos, da cotidianidade e da realidade", recorrendo no processo interpretativo ao método dialético, que, "por sua vez, ao sublinhar o dissenso, a mudança e os macroprocessos, pode ser fartamente beneficiado pelo movimento hermenêutico que enfatiza o acordo e a importância da cotidianidade”. (MINAYO, 2010, p. 349)

A pesquisa observou as implicações éticas e obedeceu aos aspectos éticos constantes na resolução 196/96 do Conselho Nacional de Saúde (CNS). As identidades dos sujeitos e da empresa foram ocultadas a fim de garantir o anonimato e a confidencialidade, portanto, os nomes apresentados dos informantes-chave e da empresa são nomes fictícios nomeados pelos pesquisadores. O projeto foi submetido ao Comitê de Ética em Pesquisa (CEP) da Escola de Enfermagem da Universidade Federal da Bahia (EEUFBA) sob o número 182.876 e foi aprovado. 


\section{O contexto de implantação do complexo automotivo}

A implantação do CIEN em Camaçari obedeceu à lógica de incremento da produção de veículos para o mercado interno e exportação para países da América Latina e está ancorada no signo da reestruturação produtiva mundial. Com a necessidade de reduzir os custos da produção, as indústrias automotivas têm migrado para países periféricos e para regiões periféricas nesses países.

De acordo com Gomes (2012), nos últimos anos ocorreu um processo de descentralização geográfica do setor automotivo, sendo que até a década de 1990, a maior parte das montadoras se encontrava na região do ABC Paulista, e hoje veículos automotores são fabricados em diversas regiões do país, com destaque para a Bahia onde a fábrica da empresa no município sede é responsável pela montagem de cerca de $10 \%$ dos veículos nacionais. Esse processo de interiorização ainda em curso do setor automotivo, com previsão de novas fábricas para Bahia e Pernambuco, é reflexo das constantes reestruturações produtivas vividas pelo setor após a crise do Fordismo na década de 1980, que obrigou a chegada de fábricas ao país e das diversas movimentações do governo brasileiro para expandir a indústria automobilística no país.

O complexo iniciou suas atividades oficialmente em outubro de 2001, modificando de forma profunda a estrutura socioeconômica do município sede. Parte dessa mudança se deu principalmente no setor de serviços pelo fato de que no acordo para a instalação da fábrica foi exigido contratação de mão de obra local. Tânia Franco (2009) descreve que a mão de obra empregada é composta por 79\% de residentes em município sede e Dias D’Ávila e por apenas $17 \%$ de residentes em Salvador, possibilitando com esse novo cenário uma nova urbanização desse município.

Ainda que o município sede tenha vivido um importante processo de industrialização no passado, os elementos da reestruturação produtiva e o lugar em que os trabalhadores "não especializados" cumpriam nesse processo produtivo são elementos que viabilizam a construção do imaginário do CIEN como um novo ciclo de possibilidades para os trabalhadores da cidade.

Sobre esse aspecto Minayo (2004) corrobora ao analisar as expectativas pela implantação de uma mineradora no estado de Minas Gerais e o processo de vinculação de trabalhadores não especializados à empresa. A autora destaca que entre as expectativas coletivas dos trabalhadores "braçais" contratados na implantação da mineradora estava que a empresa seria a "mãe", 
a "salvadora" ou a "promotora do progresso", mostrando que o processo de implantação de grandes empresas em pequenas cidades trazem processos comuns de criação de expectativa na população trabalhadora.

\section{O sonho metalúrgico: a chegada}

Na época da chegada do CIEN ao município sede, a maior parte da população economicamente ativa se encontrava trabalhando na indústria, sendo que a maior parte estava inserida na indústria química. Druck (1995) revela que a indústria petroquímica instalada em município sede empregou poucos trabalhadores da região, quadro que vai se acentuar com o processo de reestruturação produtiva vivido pelo setor, restando para a maioria dos trabalhadores a precarização do trabalho nas empresas terceirizadas. No final da década de 1990, a situação do emprego na região metropolitana de Salvador era bastante preocupante, o que serviu de estímulo para a disputa travada com o estado do Rio Grande do Sul pela instalação do complexo automotivo no município sede. A política de contratação de trabalhadores da região era a oportunidade dos antigos operários que estavam nas terceirizações do polo petroquímico, na construção civil ou para os jovens que estavam no setor de comércio e serviços poderem se inserir no setor industrial em busca de melhores salários, reconhecimento social e melhores condições de vida.

Quando eu comecei o curso [treinamento para entrar no CIEN], o que eu queria eram as vantagens, plano de saúde, salário certinho, participação em resultado. Era isso que a gente imaginava [...]. (Hugo)

A fala de Hugo é reveladora das expectativas existentes para a entrada no novo mundo que se abria na cidade de Camaçari. Jovens como ele, que estavam em outros setores, poderiam ser absorvidos pela indústria, não mais na condição de terceirizados e precarizados, mas trabalhando para uma empresa mundialmente conhecida. Seriam operários da empresa principal e usufruiriam de todos os benefícios que essa condição oferecia.

É o seguinte: ser metalúrgico foi a vinda da EMPRESA pra cá, aí surgiu aquela especulação, todo mundo tinha vontade, um sonho de trabalhar numa empresa, numa montadora, que aqui no Nordeste foi a primeira [...]. (João) 
Ah, as pessoas fora, ave Maria, era o sonho de todo mundo. A gente achava que como era uma empresa mundialmente conhecida, que ela é americana, a gente achava que ia ganhar dinheiro, que o serviço, a qualidade ia ser diferente do que eu já vi por aí a fora [...]. (Júlio)

Júlio e João confirmam o que foi dito por Hugo, as expectativas eram de ir para uma grande empresa e ter um emprego diferente dos anteriores, a oportunidade de mudar de vida, realizar os sonhos. Minayo (2004) encontra situação parecida sobre o processo de instalação de um setor produtivo em uma localidade formada por trabalhadores em precárias condições, mas gerando na região uma expectativa de mudança de vida e de aquisição de novos saberes.

Borges (2007), discutindo as transformações no mercado de trabalho brasileiro, destaca que o que observamos no município sede - precarização e terceirização no setor industrial - “[...] foram puxadas pela retração do emprego industrial, pela acentuação da divisão sociotécnica do trabalho - que propicia o surgimento de novas atividades de serviço - e pelo intenso processo de terceirização [...]”. (BORGES, 2007, p. 91, grifo nosso) A autora destaca que esse processo leva a uma transferência de postos de trabalho do setor industrial para o de serviços. A observação dessas transformações é importante para percebermos a organização do trabalho na RMS e como a chegada do CIEN vai alterar o trabalho industrial na região.

Em que pese que o contexto do município sede seja diferenciado, pois na cidade já existia um grande polo industrial quando ocorreu a instalação do CIEN, a expectativa se deu pelo fato de uma boa parcela dos trabalhadores da região se encontrar em empresas terceirizadas no polo petroquímico, empregos informais, desempregados ou sem grandes perspectivas de crescimento profissional, caracterizando-se por uma inserção precária no mercado de trabalho à época da implantação do complexo.

Na época não tinha formatura boa, como hoje também não tenho uma formatura. Tenho apenas segundo grau e alguns cursos assim como esse que eu fiz de montagem da EMPRESA, tenho esse curso que eu fiz de vigilante. [...] Quando eu entrei, achava até que ia sair de lá formado em alguma coisa, eu até optei por montagem porque eu achei que ia trabalhar, se tivesse oportunidade, que ia montar um motor, aí eu achei que ia conhecer a parte mecânica... Achei que eu ia aprender, imaginei que eu ia aprender mais coisa, como eu fiz o 
curso de montagem, aí eu achei que chegar lá, ia trabalhar montando peça, ia botar assim um motor, ia desenvolver ali, ia saber cada peça o que ia fazer. [...] Eu fiquei achando que ia sair daqui como técnico. (Luiz)

A fala de Luiz revela o desejo por formação profissional que existia nos homens que entraram no processo produtivo do complexo automotivo. A falta do conhecimento sobre modo de produção da empresa, com especialização em poucas tarefas, orientada pelo modelo Taylorista, levava os trabalhadores a idealizarem um trabalho que permitiria a aquisição de saberes de tal complexidade que lhes permitiria montar e desmontar um carro, nos quais deixariam de ser um operário pouco qualificado para assumir um importante papel no processo produtivo metalúrgico.

O perfil desse trabalhador com baixa escolaridade e formação profissional revela a situação de vulnerabilidade que estava presente na implantação do CIEN. O sonho de entrada no complexo estava posto para as camadas populares da cidade, para aqueles trabalhadores que estavam inseridos em setores terceirizados no processo produtivo petroquímico, nos serviços ou em subempregos e que encontrou no setor automotivo a possibilidade de ter mais que um emprego, uma identidade profissional.

O sonho de entrada no complexo automotivo se concretizou para milhares de trabalhadores de município sede e região. Se no ano de 2000 o setor automotivo não representava nem $1 \%$ do estoque de empregos formais na cidade, em 2010 passou a representar cerca de 10\%, empregando aproximadamente 7.800 trabalhadores. (BRASIL, 2010) Nesse mesmo período, o município sede vivenciou um dos maiores crescimentos econômicos do estado da Bahia, saindo do número de 29.165 empregos formais para 76.411, sendo o setor automotivo um dos principais catalisadores desse crescimento. Empregos diretos, com a geração de empregos no setor e de forma indireta, com a criação de uma classe trabalhadora com maior poder de compra na cidade em que se passou a demandar mais oferta de produtos e serviços.

Franco (2009) discute o processo de chegada do CIEN, destacando o papel que essa implantação teria na inversão da lógica aplicada na industrialização no setor petroquímico. Os acordos para a implantação do CIEN buscavam destinar a inserção da maior parte da força de trabalho da produção com trabalhadores do município sede e região, buscando 
modificar o processo a que destinou os trabalhadores "especialistas" residentes em Salvador, os empregos diretos no polo petroquímico e os piores empregos nas terceirizadas para os residentes na região metropolitana de Salvador.

\section{A construção da identidade metalúrgica}

Você vê todo mundo azulzinho, fardado. Acho que a gente sentia orgulho. Eu tinha muito orgulho de trabalhar numa empresa como a multinacional [...]. (Júlio)

A implantação do CIEN, principalmente a partir do ano de 2002, com a planta em pleno funcionamento, propicia a formação na cidade de um grupo operário majoritariamente formado por homens moradores do município sede, com características parecidas, que ganha destaque por passar a trabalhar no complexo e desfrutar de salários bem acima dos recebidos em outros setores econômicos da cidade. Como já discutimos antes, passam a ser trabalhadores diretos de uma importante multinacional. A fala de Júlio revela um importante sentimento dos trabalhadores que estiveram à frente do processo de implantação e consolidação da planta em município sede. $\mathrm{O}$ orgulho metalúrgico passa a ser parte da construção da identidade de um grupo que aos poucos vai ganhando um reconhecimento social na cidade.

Chegando ao município sede, você sente a presença do CIEN, mesmo que você não veja a fábrica, que fica numa região industrial distante do centro da cidade. Não é incomum andar pela rua e ver trabalhadores com a farda do complexo, mesmo em horários distantes da passagem do roteiro (ônibus que levam os trabalhadores a fábrica). Não vi ninguém pela rua com a farda da principal petroquímica, mas do complexo, da rodoviária até chegar à unidade avistei vários trabalhadores. Acho que isso tem a ver com o reconhecimento social de ser trabalhador da EMPRESA na cidade [...]. (Diário de campo, 28 de março de 2012)

Dentre os elementos de constituição da identidade metalúrgica no município sede, a constituição da identidade de classe através do fortalecimento do sindicato é um fato marcante. Ismar Sena (2009) revela que, no momento da implantação do complexo automotivo, uma disputa sindical se deu entre representantes do Sindicato dos Metalúrgicos da Bahia ligados à 
CTB, e um grupo de sindicalistas ligados a Força Sindical de São Paulo, que tinham como objetivo a criação de um sindicato local no município sede. Dessa disputa nasce o Sindicato dos Metalúrgicos do município sede, ligado ao sindicato estadual e à CTB, que precisa dar respostas rápidas para a categoria metalúrgica.

Em 2003, os metalúrgicos do município sede vivenciam a primeira importante greve da categoria. Uma categoria jovem, sem experiência sindical, que se enfrenta com a direção da empresa com uma pauta de equiparação salarial com os salários da montadora no sudeste. Nesse momento, é possível perceber a conformação de uma identidade coletiva, de um sentimento de orgulho por ser da categoria metalúrgica no município sede, que é produzido através do movimento de luta dos trabalhadores por melhores salários e por mais reconhecimento da planta do município sede.

Sou metalúrgico, com muito orgulho, sou da Bahia, quem não queria?

Sou Baiano, sou cabra da peste, sou nordestino sou trabalhador não tenho nada de menino $[. .$.

Tem gente fazendo carro, lugar do pólo industrial, aqui tem especialista respeitado cheio de moral [...].

(Trecho de música escrita por um operário do CIEN na época da greve de 2003)

A letra da música, utilizada pelo sindicato até os dias atuais, revela a afirmação da metalurgia automotiva no município sede, a possibilidade de trabalhadores tidos como braçais produzirem carros, mostrando a disputa com a empresa, na qual não ser menino significa não aceitar as condições de trabalho dadas pelo CIEN, os baixos salários e o assédio que já estava claro no ano de 2003.

João Bosco Santos (2000) considera que a identidade social é a soma dos papéis assumidos pelos sujeitos, sendo o trabalho um importante espaço de produção de identidade social. $\mathrm{O}$ autor faz ainda uma importante discussão sobre o papel que o trabalho cumpre na conservação da identidade social e no sentimento de pertença dos indivíduos. No município sede, é latente esse sentimento de pertença, o orgulho que os metalúrgicos possuem por estarem num emprego desejado por muitos, que o trecho da música faz questão de ressaltar, “quem não queria?”. 


\section{Satisfação e impacto econômico e social do trabalhar no CIEN}

Esse processo de consolidação de uma nova identidade na cidade de município sede, a partir da constituição de uma nova classe trabalhadora, é mediado por uma perceptível ascensão social desses trabalhadores. A fábrica permitiu que centenas de trabalhadores comprassem casa, carro, mantivessem filhos em escolas particulares, mudando a vida de uma parcela de trabalhadores do município sede.

Tenho dois colegas que eram garis, coletadores de lixo mesmo, que hoje trabatham lá. Eles têm orgulho sim, porque eles saíram do nada, do quase nada, pra tudo, não é? Eu tenho um colega que antes ele falava assim: Hugo, eu morava na casa da minha sogra, eu passava humilhação e hoje eu tenho a minha casa e hoje a minha sogra tá morando comigo. Entendeu como reverteu a situação? [...] Entre trabalhar no comércio e trabalhar na EMPRESA, tem que trabalhar na EMPRESA! A diferença é muito grande, de salário mesmo, é o dobro do salário. Você vai ter esse diferencial. Fora essa questão de no final do ano a gente ter a participação em resultados, que hoje é quase dez mil reais. [...]. (Hugo)

A mudança trazida pelos novos salários, fornecimento de plano de saúde e ganho de PLR $^{3}$ proporciona aos trabalhadores a realização de planos nunca antes imaginados. Cria na cidade um conjunto de trabalhadores com maior poder aquisitivo, movimenta o comércio local, gera um novo ciclo de crescimento. $\mathrm{O}$ trecho acima revela como a mudança no reconhecimento social se dá no cotidiano, no qual trabalhadores que estavam nas piores inserções no mercado de trabalho passam a compor a força de trabalho de um novo setor, mudando por completo a sua vida.

Para além dos impactos financeiros relatados por nossos informantes, a identidade social dos metalúrgicos do município sede também se constitui pelo sentimento de pertença a uma categoria consolidada. Ainda que não seja um petroleiro, emprego sonhado por muitos no estado da Bahia, ser parte da categoria metalúrgica, trabalhar no CIEN, representa um diferencial para o restante dos trabalhadores da cidade e da região, incluindo esses homens no mundo do trabalho não apenas na cidade, eles passam agora a ser reconheci-

3 Participação nos Lucros e Rendimentos. 
dos como trabalhadores de uma empresa que tem plantas em vários lugares do mundo, passam então a ter uma importância antes não imaginada.

Rapaz, na verdade. A gente sente até um prazer de trabalhar numa empresa de grande porte como é a EMPRESA, ou uma parceira, certo? Na questão do salário, não é ruim. Se eu disser a você que é ruim, eu estou mentido pra você. Tem a questão do plano de saúde, que ajuda você a fazer uma cirurgia, como eu já fiz duas. Se eu não tivesse plano, não poderia ter feito. Questão da vida social, econômica, que melhora um pouco. Tem a PL (participação nos lucros) que com muita luta a gente conseguiu, o sindicato conseguiu [...]. (Júlio)

Dados do DIEESE mostram que na implantação do CIEN, o salário médio de um trabalhador da produção era cerca de três vezes menor que a média na região do ABC Paulista. Em 2005, mesmo com um aumento significativo da remuneração média no município sede, que sai de $\mathrm{R} \$$ 608,36 em 2001 para $\mathrm{R} \$ 1.297,93$ em 2005, ainda há um grande abismo entre os salários do CIEN e dos trabalhadores da empresa em São Paulo. $\mathrm{O}$ estudo comenta ainda que a justificativa das empresas para que o salário no município sede seja menor é devido ao menor custo de vida. O que não se confirma, pois, em pesquisa realizada sobre os custos e poder de compra dos trabalhadores, observou-se que não existem diferenças significativas entre os custos de vida das regiões de produção automotiva que justifiquem uma discrepância salarial como a existente. (DIEESE, 2003, 2007)

Fato é que o ingresso no CIEN transforma a vida dos trabalhadores do município sede, levando-os a experimentarem sensações de satisfação no trabalho durante muito tempo, pelo potencial transformador social que o trabalho passa a mediar.

Eu gostava pelos meus colegas, assim, a gente criou aquele vínculo de amizade. Era um sofrimento, mas tinha alegria. [...]. (João)

Eu era uma pessoa dedicada, gostava de fazer mesmo nessa operação, gostava de trabalhar ali. Eu me sentia orgulhoso quando eles diziam que era o operador, melhor operador de painel, mesmo sofrendo, mesmo com aquelas dificuldades, mas eu me sentia orgulhoso de ser [...]. (João)

A fala de João revela dois componentes do trabalho promotor de satisfação. A relação com os colegas de trabalho, que ajuda a criar no indivíduo 
uma identidade social e o prazer pelo reconhecimento social do seu trabalho e da sua utilidade são elementos potenciais do trabalho na transformação da vida dos sujeitos. Mesmo em situações de adversidade no trabalho, as características de satisfação também estão presentes e elas parecem se configurar como importantes fatores de apoio para se manter trabalhando mesmo em face de adversidades.

Eu tenho orgulho de ser empregado, porque é disso que a gente sobrevive. Mas esse orgulho de ser metalúrgico é só ficção. Quando você cai na realidade, você vê que o negócio não é bem isso que a gente pensa [...]. (João)

O enunciado apresenta uma importante contradição do mundo do trabalho. O mesmo trabalho que produz identidade, que tem um componente de satisfação, também carrega adoecimento, desconstrução de identidade e de sofrimento. Ao entrar na fábrica, os operários começam a perceber que a realidade era mais dura do que os sonhos e expectativas que conseguiam pensar.

Ninguém imagina que vai encontrar o ambiente ora insalubre, ora maléfico para a saúde, seja ergonomicamente ou psicologicamente, porque (suspiro) o que acontece lá dentro, se você for observar, se você tiver a oportunidade de entrar na empresa, você vai ver um monte de loucos trabalhando, eles não param, não param para nada. É, sai uma peça de um lado, já está entrando outra. A rotatividade é intensa. Tem um ritmo frenético. (Hugo)

O processo produtivo é marcado pela intensidade, na qual os ritmos da produção são incompatíveis com a capacidade do corpo. Tânia Franco (2011) discute a problemática dos processos produtivos, no qual os "tempos sociais” - tempos engendrados pelo ritmo do capital - não são compatíveis com os “tempos naturais" - tempos biopsicossociais. Esse ritmo de trabalho determinado pela linha de produção, que não para, que é frenético, adoecedor, é fruto de um processo produtivo com que se combina características de controle excessivo dos tempos e movimentos de uma produção acelerada para acompanhar os ritmos do mercado.

É muita pressão, muito foco, pouca valorização, pouca importância com a saúde do funcionário. O foco era produção, produção, produção e não esquecendo que pra isso acontecer teria que ter um funcionário para poder tra- 
balhar e produzir [...]. A gente fabricava era quatrocentos carros no turno, trezentos ou quatrocentos carros no turno. Imagine você trabalhar oito, nove horas de trabalho, fazendo aquela mesma coisa, escutando aquela mesma coisa [...]. (João)

Esse modelo produtivo que, de acordo com Ricardo Antunes (2002), combina características de gestão do trabalho típicas do Taylorismo/ Fordismo associadas com a especialização flexível toyotista, permitindo impor uma maior velocidade à produção, tem sido responsável por um importante impacto no perfil de adoecimento dos trabalhadores no município sede.

Os dados da unidade de saúde reforçam essa ideia. Há evolução da procura por atendimento na unidade de saúde do trabalhador do município sede no período de 2003 a 2011. Comparando os dados com o estudo de Silva (2002), observa-se que, após a implantação do CIEN, a procura pelo serviço passou a aumentar, tendo como ápice os anos de 2005, 2006 e 2007. Os dados ainda revelam que de toda a demanda atendida no período referido na unidade, $18,2 \%$ foi gerada por trabalhadores do setor automotivo, sendo a maioria homens com idade de até 40 anos.

É importante destacar que, a partir de 2008, há um descenso no número de trabalhadores do CIEN atendidos no CEREST. As evidências encontradas não apontam para um descenso causado pela melhoria das condições de trabalho no CIEN e sim pela mudança na política de reconhecimento de benefícios pela previdência social. Com a constituição do Nexo Técnico Epidemiológico Previdenciário em 2007, o número de trabalhadores que procuram o CEREST diminui. Essa diminuição pode ser explicada pelo fim da exigência de possuir uma Comunicação de Acidentes de Trabalho (CAT) para ter acesso à concessão de auxílio doença-acidentário (B91) pela previdência social. (CODO, 2010)

Ao observarmos essa evolução no período, é possível notar que há um acúmulo de trabalhadores buscando o serviço de saúde com pouco tempo de trabalho, o que pode ser explicado pelo processo de trabalho desgastante, pela forma de implantação do complexo, que iniciou a produção com baixo número de operários, com estrutura sem adequação às necessidades de saúde, fazendo com que os metalúrgicos utilizassem do corpo como auxiliar do processo produtivo. Mais que operar máquinas, eles precisavam em alguns momentos substituí-las. 
Esses homens, que em comum possuem o fato de terem participado da implantação e do desenvolvimento inicial da indústria automotiva na Bahia, vivenciaram um processo produtivo marcado pela disputa de mercados e consolidação da produção. Os altos investimentos realizados para a instalação da empresa precisariam retornar rapidamente e por isso o aumento da produção com destinação ao mercado interno e às exportações fixavam para os trabalhadores um trabalho acelerado, no qual o ritmo da linha de produção era quem ditava as ordens, as quais os trabalhadores usavam de si para dar conta do processo produtivo.

\section{"A gente fazia tudo aquilo manual": Usos de si para dar conta do processo produtivo}

Ela deve ter uns nove a dez quilos e a gente manuseava. Na época não tinha os dispositivos pra retirar, para pegar uma peça e a gente fazia tudo aquilo manual. Para você ter uma ideia, eu tirava da esteira três peças por hora [...]. Associado a isso tinha peças que eu tinha que retirar que a gente mandava pra Venezuela [...] Então, isso todos os dias. [...] E eu trabalhei dez meses seguidos em uma única operação [...]. (Hugo)

O cotidiano do trabalho, no início da produção do CIEN, foi marcado pela sobrecarga, horas extras, falta de equipamentos que levavam os trabalhadores a usarem do seu corpo para dar conta das demandas da produção. O que estava em jogo para esses trabalhadores era a necessidade de se mostrar produtivo, mesmo que para isso precisassem levar o corpo ao limite, trabalhar sob o ritmo das máquinas, muitas vezes substituindo-as.

Só que o nosso manipulador da empresa não era igual ao da parceira lá não. Lá era manual mesmo, o sistema de ar comprimido despressurizava com você como painel na mão. Era muita força que você tinha que usar. E aí você recebia aquele peso todo e você tinha que segurar. E aí fazer o jogo assim pra jogar pra dentro do carro. E aí era um carro atrás do outro. [...] E aí, meu irmão, era o tempo todo assim. Agora você me responda: tem condições de um ser humano aguentar um negócio desse e dizer que não sente nada? [...]. (João)

O setor da montagem final no CIEN é marcado pelo ritmo acelerado de trabalho, no qual a linha de produção dá o ritmo do trabalho, que deve ser o mais intenso para dar conta da alta produtividade da planta, e, na maior 
parte das vezes, os tempos da produção não correspondem às necessidades impostas pela tarefa prescrita, fazendo o trabalhador usar de si para dar conta da tarefa. A contradição colocada é que mesmo estando presente no ambiente, o que Ive Clot (2001) chama de atividade impedida, os trabalhadores "se viram" para se manter no emprego, e vão dando conta até que o corpo não suporte mais a pressão da produção. Para esse autor:

O real da atividade é também o que não se faz, aquilo que não se pode fazer, o que se tenta sem conseguir - os fracassos - aquilo que se desejaria ou poderia fazer, aquilo que não se faz mais, aquilo que se pensa ou sonha poder fazer em outro momento. [...] Atividade é aquilo que se faz para não se fazer o que tem que ser feito ou ainda o que se faz sem desejar fazer. (CLOT, 2001, p. 6)

Nesse sentido, ao analisarmos a atividade relatada pelos operadores na linha de produção, podemos perceber as reinvenções cotidianas que esses trabalhadores precisam fazer para dar conta "do que deve ser feito" num ambiente totalmente contraditório.

De um lado a tarefa prescrita - montar o painel do carro em um tempo definido - do outro a velocidade da linha de produção, a falta de equipamentos e os riscos de parar a linha, acumular carros na montagem ou deixar peças caírem do manipulador, o que recairia sobre o trabalhador, que "é lento", ou que "emperra a produção" como relatou Luiz, ou ainda que é "lerdo" e deixa as peças caírem do manipulador”, medo enfrentado por João. Os discursos elucidam o que Ive Clot (2001) chama de disponibilidade psíquica cada vez maior que impele os trabalhadores a colocarem cada vez mais de si no trabalho.

Na fala do operador, ele mostra a contradição entre o prescrito e o real no trabalho, entre todos os rearranjos que ele precisa fazer deliberadamente para dar conta da atividade. Fica claro que o início do processo produtivo no complexo foi marcado pela necessidade constante de uso de si pelos trabalhadores para a atividade que se impunha.

As escolhas feitas pelos trabalhadores para se manterem produtivos, $\mathrm{e}$ nos empregos no momento de alta competitividade no complexo, mostra que estas escolhas têm levado a situações de sofrimento e, infelizmente, apesar de chamarmos esse processo de escolhas, outras alternativas não são dadas aos trabalhadores que precisam "se virar" no cotidiano para cumprir as tarefas. Sobre isso Ive Clot (2001, p. 5) diz que "[...] é uma ati- 
vidade contrariada, um desenvolvimento impedido. É uma amputação do poder de agir”.

Porque é um esforço repetitivo, porque você anda o dia todo de ré. Têm retrovisores, mas a segurança não queria que olhasse só o retrovisor porque às vezes você olhava de um lado e o pedestre já tava do outro lado e você num via. (Júlio)

Para você ir ao banheiro você tinha que ver alguém, que a linha num para, a linha num para, vocêficava apertado pra ir ao banheiro [...] Porque acham que você tem que ficar o mínimo possível no banheiro, ir correndo e voltar correndo. [...] Às vezes vocêfica uma hora, duas horas pedindo pra ir ao banheiro e nada de ninguém chegar e dizer, ah, vou tirar o seu banheiro. Já aconteceu de ter gente de parar a linha de produção. Eu já parei a linha de produção pra ir ao banheiro [...]. (João)

Nota-se nas falas dos trabalhadores que o seu poder de agir é tolhido pela organização do trabalho, em que a atividade fim é impedida, bem como os desejos de fazer "bem feito" são repensados a todo o momento. O trabalhador precisa fazer escolhas e faz usando mais de si, do seu corpo, da sua saúde, não fazendo pausas, forçando o uso de um segmento do corpo, dirigindo em posição desconfortável ou tantas outras situações encontradas no cotidiano do processo de trabalho. Podemos compreender essa situação, a partir de Ive Clot (2001), como uma “atividade envenenada” pela diminuição dos trabalhadores.

Quando se observa o trabalho real, vê-se que esse é totalmente diferente do prescrito, pois a partir da observação das modulações realizadas percebe-se que não daria conta de atingir os objetivos traçados.

Olhar apenas para o realizado jamais nos daria dimensão da "luta cotidiana" que travam esses operadores. Aqui fica claro que o realizado não possui o monopólio do real, e que esse real é muito maior do que podemos imaginar, e ele é elaborado cotidianamente pelos trabalhadores que precisam fazer suas escolhas.

É certo que essas escolhas, neste contexto, trazem diversas consequências para esses trabalhadores como o adoecimento físico, a sensação de fracasso, a hipersolicitação constante. O uso do si desse "destino a ser vivido" tem seu preço. Ive Clot (2001, p. 6) diz que

A fadiga, o desgaste violento, o estresse se compreende tanto por aquilo que os trabalhadores não podem fazer, quanto por aquilo que eles fazem. As atividades suspensas, contrariadas ou im- 
pedidas, e mesmo as contra- atividades, devem ser admitidas na análise assim como as atividades improvisadas ou antecipadas. A atividade removida, oculta ou paralisada não está ausente da vida do trabalho. A inatividade imposta - ou aquela que o trabalhador se impõe-pesa com todo o seu peso na atividade concreta.

Os usos de si explica o fenômeno do adoecimento tão precoce nessa população de trabalhadores do setor automotivo. A combinação de elementos como a organização do trabalho e as condições nas quais esse trabalho é desenvolvido levou centenas de trabalhadores do complexo automotivo a procurarem os serviços de saúde. É possível perceber a partir das narrativas desses trabalhadores que aquilo que se faz - movimentos repetitivos, posturas anômalas, hipersolicitação do corpo - está tão relacionado com o adoecimento quanto o que não se pode fazer - não se pode realizar como se deseja, não pode se permitir pausas, não se pode ajustar o prescrito, não se pode fazer o que se tinha vontade etc. -, reforçando a tese que os processos de adoecimento são construídos no cotidiano, nas contradições de um trabalho vivo, em que a todo momento coloca sobre os trabalhadores a decisão entre o possível e o impossível. Observamos surgir o sofrimento e o adoecimento no trabalho em constante conflito com o orgulho metalúrgico e o prazer no trabalho.

Ela quer quantidade de carro, no final do turno atingir a meta e acabou [...]. Resumindo: "Você lá é um parafuso a mais. Aluiu, joga fora e bota outro [...]. (João)

Os conflitos gerados pelo processo de trabalho que leva centenas de trabalhadores a adoecerem, faz com que estes passem a se perceber como uma parte descartável do processo de trabalho, usados apenas para compor a grandiosa engrenagem produtiva e lança-los fora a qualquer tempo em que não sirvam mais para o processo produtivo. Nesse momento, passa a compor esse cenário um forte sentimento de não pertencimento, aprofunda-se o estranhamento no trabalho, pois agora confirmando o que disse Marx (2006, p. 82): "quanto mais [...] cria, mais [se torna indigno e sem valor], quanto mais bem formado seu produto, [...] mais deformado ele fica”.

$\mathrm{O}$ adoecimento na fábrica permite, por um momento, que o trabalhador deixe apenas de pensar no trabalho, passe a se ver no processo e inclusive a questionar o processo. Questiona, ao passo que compreende a lógica de fun- 
cionamento do capital, percebe que seu trabalho foi apropriado por outro, sua força de trabalho foi usada até o esgotamento e que agora ele está desamparado.

O problema é que se exige muito e devolve-se pouco, como sempre foi a relação patrão-empregado [...] A empresa na minha opinião, eu posso estar errado também, pode ser de certa forma, que eles se preocupem de alguma forma com quem tá fora, mas nunca me perguntaram nada, nem se eu estava bem, mal, nem se eu precisei nada. (Hugo)

É possível perceber como as contradições capital-trabalho se expressam no cotidiano e são despercebidas para muitos trabalhadores, ou são compensadas por recompensas de um salário acima da média da cidade, ou por ganhos com a Participação nos Lucros e Rendimentos (PLR). Para os trabalhadores que adoeceram no trabalho, elas ganham um contorno mais claro, pois há uma real percepção de que foi da dualidade entre capital-trabalho, homem-máquina, patrão-empregado que se determinou seu adoecimento. Os trabalhadores sentem "na pele" o produto da lógica capitalista, como diz Harvey (1992), se apoiam na extensão da jornada de trabalho, na transferência de capitais de regiões de altos salários para regiões com baixos salários, mudança organizacional e tecnológica, utilizando-se de trabalhadores de lugares em desenvolvimento onde existe ausência de contrato social com o trabalho ou onde esses contratos têm pouca força.

Dessa forma de produção, na qual os trabalhadores são vistos como mais uma peça do processo produtivo, da qual é possível adaptar a qualquer momento para novas formas de organização do trabalho, surgem situações que produzem iniquidades em saúde. $\mathrm{O}$ adoecimento no complexo automotivo é mediado pelo processo produtivo e pelas condições socioeconômicas dos trabalhadores, que não permitem que os mesmos abandonem o processo produtivo, mesmo quando percebem que estão adoecendo no trabalho. Somado a isso, a ausência do Estado na proteção do trabalhador, ao tempo que é presente na garantia das condições de produção para as empresas, aprofundam essas desigualdades, pois em grande medida abandona os trabalhadores à própria sorte, deixando-os perdidos em busca de reparação social pelas perdas que tiveram.

O que mais me incomoda é a desatenção que a gente tem por parte da empresa e por parte dos órgãos competentes [...] É uma desatenção total do Ministério do 
Trabalho, de não se preocupar mesmo. Parece que a gente busca a doença. Não é assim. [...] Cadê o interesse da empresa no trabalhador. Eu não sou funcionário da empresa? [...] Essa inércia do Estado com a nossa situação é que me incomoda. [...] O que será que o ministério do trabalho não está enxergando? O que será que o CREMEB não observa esses lesionados? A própria justiça do trabalho, não é mais imperativa com essa empresa? Qual o prejuízo que a sociedade vai ter daqui a mais de dez anos, com esse bando de lesionados dependendo de benefícios de INSS? (Hugo)

As narrativas revelam o desespero de trabalhadores que entraram sadios no processo de trabalho, viveram a fábrica na máxima intensidade, doaram-se na busca de construir um sonho. A percepção de que a empresa está “virando as costas" para eles e de que o Estado é omisso, só amplia a magnitude do problema vivenciado pelos trabalhadores, que começam a perceber e questionar o porquê do Estado não se mostrar mais presente, não usa da mesma força que usou para beneficiar a empresa na época da implantação, agora para ajudar os trabalhadores.

Hugo questionou o que, para Harvey (2008), nada mais é do que o papel previsto do Estado neoliberal. Em caso de conflito, tende a ficar favorável ao capital em detrimento dos direitos - e da qualidade de vida - dos coletivos de trabalhadores. A esse novo Estado é dada a função de manter a "integridade do sistema financeiro e a solvência das instituições financeiras e não o bem-estar da população ou a qualidade ambiental”. (HARVEY, 2008, p. 81) É em meio a esses conflitos entre capital e trabalho que se expressam as experiências dos trabalhadores com seus empregadores ou com o Estado. Os trabalhadores com LER/DORT vão experimentando a perda da capacidade para o trabalho e sentindo-se cada vez mais desamparados.

Se o tempo voltasse, fazia tudo diferente. Eu ajudei muito a empresa, hoje em dia não estou sendo ajudado. (Ubaldo)

O processo vivenciado pelos trabalhadores do complexo automotivo do município sede traz em si percepções contraditórias ao tempo em que ser trabalhador do CIEN era motivo de orgulho, sendo esse processo responsável pela formação de uma identidade coletiva, mas também por um duro processo de adoecimento que desconstrói, os traços de uma identidade coletiva construída. $\mathrm{O}$ adoecimento e incapacitação são mediados diretamente pelo modelo de produção capitalista, pela organização do processo produtivo, que 
reúne um hibridismo organizativo com características do modelo taylorista-fordista, somadas às características da acumulação flexível, que, em se tratando de uma cidade em uma das regiões menos desenvolvidas de um país periférico, ganha contornos ainda mais danosos para o trabalho.

Mediado ainda por um Estado que se distingue por características neoliberais, ausente na proteção do bem estar da população e presente para o grande capital, o processo de adoecimento acontece isolando os trabalhadores, que passam a ser o "peso morto" no trabalho, os queixosos, os que só querem reparação, os que incomodam a empresa e o Estado na busca por justiça social. Destaca-se ainda nesse processo a ausência da pauta da saúde dos trabalhadores com centralidade na intervenção sindical. A centralidade da luta por salários e a não priorização da luta contra o adoecimento no trabalho são elementos que explicam a situação em que se encontram os trabalhadores do complexo. É nesse contexto que os sonhos vão sendo desconstruídos. Os trabalhadores passam a perceber que o sonho metalúrgico ficou para trás, que passa a ser um não orgulho marcado pelo abandono da empresa e do Estado. Materializa-se então o sentimento de homens descartáveis, parafusos, máquinas, que ao se detectar um defeito devem ser substituídos por outros, para que assim, com novas peças prontas para uso, a produção continue. Ainda que o preço disso seja cada vez mais homens adoecidos, incapacitados e com sonhos interrompidos.

\section{Referências}

ANTUNES, R. Adeus ao Trabalho? ensaio sobre as metamorfoses e a centralidade do mundo do trabalho. 8. ed. São Paulo: Cortez: UNICAMP, 2002.

BORGES, A. Mercado de trabalho: mais de uma década de precarização. In: DRUCK, M. G.; FRANCO, T. (Org.). A perda da razão social do trabalho: terceirização e precarização. São Paulo: Boitempo, 2007.

BRASIL. Ministério da Previdência Social. Anuário Estatístico da Previdência Social 2010. 2011. Disponível em: <http://www.mps.gov.br/arquivos/ compressed/3_111007-155436-292.zip >. Acesso em: 31 out. 2011. Seção IV Acidentes do Trabalho.

BRASIL. Ministério do Trabalho e Emprego. Relatório Anual de Informações Sociais. Brasília, DF, 2010. 
CLOT, Y. Clínica do trabalho, clínica do real. Tradução de Kátia Santorum e Suyanna Linhales Barker. Le Journal dês psychologues, Paris, n. 185, mar. 2001.

CODO, W. Uma revolução silenciosa em saúde e trabalho no Brasil. In:

MACHADO, J. M. H.; SORATTO, L.; CODO, W. (Org.). Saúde e Trabalho no Brasil: uma revolução silenciosa: o NTEP e a Previdência Social. Petrópolis, RJ: Vozes, 2010. p. 12-19.

CONLUTAS. Homenagem aos metalúrgicos. 2008. Disponível em: <http:// cspconlutasbahia.blogspot.com.br/20o8/10/homenagem-aos-metalrgicos.html>. Acesso em: 15 jan. 2013 .

DIEESE. Sindicato dos Metalúrgicos do ABC. Do holerite às compras: remuneração, preços e poder aquisitivo do tempo de trabalho em 17 municípios com produção automobilística no Brasil. São Paulo, 2003.

DIEESE. Sindicato dos Metalúrgicos do ABC. Do salário às compras: remuneração, preços e poder aquisitivo do tempo de trabalho em 54 municípios com produção automobilística, siderúrgica e autopeças. São Paulo, 2007.

DRUCK, M. G. Terceirização: (des)fordizando a fábrica: um estudo do complexo petroquímico da Bahia. 1995. 271 f. Tese (Doutorado em Ciências Sociais) Instituto de Filosofia e Ciências Humanas, Universidade Estadual de Campinas, 1995 .

FEDERAÇÃO DAS INDÚSTRIAS DO ESTADO DA BAHIA - FIEB. Pesquisa Industrial Anual (PIA) - 2008 (sinopse). Salvador, 2010.

FORD MOTOR COMPANY. Camaçari-BA. [201-]. Disponível em: <https://www. ford.com.br/sobre-a-ford/fabricas-no-brasil/camacari/>. Acesso em: 20 fev. 2013.

FRANCO, A. Em tempos globais, um “novo” local: a Ford na Bahia. Caderno CRH, Salvador, v. 22, n. 56, p. 359-38o, maio/ago. 2009.

FRANCO, T. Alienação do trabalho: despertencimento social e desrenraizamento em relação à natureza. Caderno $C R H$, Salvador, v. 24, p. 171-191, 2011. Suplemento 1.

GOMES, R. A. Indústria automobilística como um setor-chave na estrutura produtiva de uma região: o caso do Complexo FORD de Camaçari. 2012. 85 f. Dissertação (Mestrado em Gestão Logística) - Centro de Tecnologia, Universidade Federal do Ceará, Fortaleza, 2012.

HARVEY, D. A condição pós-moderna: uma pesquisa sobre as origens da mudança cultural. São Paulo: Loyola, 1992. p. 117-184.

HARVEY, D. O neoliberalismo: história e implicações. Tradução de Adail Sobral e Maria Stela Gonçalves. São Paulo: Loyola, 2008. 
INSTITUTO BRASILEIRO DE GEOGRAFIA E ESTATÍSTICA - IBGE. Censo 2010. [2010]. Disponível em: <http://www.censo2010.ibge.gov.br/>. Acesso em: 20 fev. 2013 .

MARX, K. Manuscritos econômico-filosóficos. Tradução de Jesus Ranieri. São Paulo: Boitempo, 2006.

MINAYO, M. C. S. De Ferro e Flexíveis: marcas do estado empresário e da privatização na subjetividade operária. Rio de Janeiro: Garamond, 2004.

MINAYO, M. C. S. O desafio do conhecimento: pesquisa qualitativa em saúde. 12. ed. São Paulo: Hucitec, 2010.

SALERNO, M. S; MARX, R.; ZILBOVICIUS, M. A nova configuração da cadeia de fornecimento na indústria automobilística no Brasil. Revista de Administração, São Paulo, v. 38, n.3, p. 1-1, jul./set. 2003 .

SANTOS, J. B. F. O avesso da maldição do Gênesis: a saga de quem não tem trabalho. São Paulo: Annablume, 200o. p. 239-293.

SENA, I. N. Fábrica de lesões: trabalho, adoecimento e ação sindical no complexo automobilístico baiano. 2009. 139 f. Dissertação (Mestrado em Ciências Sociais) - Faculdade de Filosofia e Ciências Humanas, Universidade Federal da Bahia, Salvador, 20og.

SILVA, A. C. C. Estudo da demanda LER/DORT atendida na Unidade de Saúde do Trabalhador de Camaçari / USAT, no período de 1995-2001. 2002. 37 f. Monografia (Especialização em Saúde do Trabalhador) - Instituto de Saúde Coletiva, Universidade Federal da Bahia, Salvador, 2002. 